\title{
Manual de orientação de posicionamento e execuçáo de atividades da vida diária para pacientes com acidente vascular cerebral
}

\author{
Natalia Cristina Thinen ${ }^{\mathrm{a}}$, Ana Claudia Fernandes Moraes ${ }^{\mathrm{b}}$ \\ aTerapeuta ocupacional, Faculdade de Filosofia e Ciência, \\ Universidade Estadual Paulista - UNESP, Marília, SP, Brasil \\ 'Mestre em Educação, Faculdade de Filosofia e Ciência, \\ Professora substituta da Universidade Estadual Paulista - UNESP, Marília, SP, Brasil
}

\begin{abstract}
Resumo: O objetivo deste trabalho é descrever a orientação do terapeuta ocupacional para cuidadores em relação ao posicionamento no leito, as atividades da vida diária, transferência de posições e organização do ambiente durante a alta hospitalar de pacientes com acidente vascular cerebral (AVC) por meio de orientação verbal e finalizando com a entrega de um manual. Participaram do estudo 10 cuidadores. Na primeira parte do estudo, realizou-se o levantamento das dúvidas dos cuidadores a respeito dos cuidados do paciente com AVC. Na segunda parte foram realizadas as orientações aos cuidadores, a entrega de um manual com todas as informações e a avaliação do respectivo manual pelos cuidadores. Na análise dos relatos dos cuidadores constatou-se que nenhum deles tinha o conhecimento do posicionamento correto no leito, todos os entrevistados demonstraram percepção positiva com relação ao manual e relataram que as orientações modificaram a forma de cuidar do paciente. Assim, nos limites de análise deste estudo, foi possível concluir com o trabalho que os cuidadores foram instruídos e orientados, tendo condições de iniciar o processo de reabilitação no domicílio.
\end{abstract}

Palavras-chave: Terapia Ocupacional, Acidente Vascular Cerebral, Cuidadores.

\section{Manual of positioning orientation and execution of activities of daily life for stroke patients}

\begin{abstract}
The objective of this manuscript is to guide caregivers in relation to the lying position in bed, activities of daily life (ADL), position transfer, and hospital discharge preparation of Cerebral Vascular Accident (CVA) patients by means of verbal orientation, finalizing with the handing over of manuals. Ten caregivers participated in the study. The methodology consisted of two phases: in the first part of the study, a survey was conducted on caregivers' doubts regarding the necessities of Stroke patients; in the second part, orientation was provided to caregivers and the information manuals were handed over; caregivers were also requested to evaluate the respective manuals. Results showed that none of the caregivers knew the correct positioning of the patient in bed and, considering the illustrations and the objectivity of the manual, all caregivers interviewed demonstrated positive perception regarding the manual, and reported that its guidance improved their way of caring for patients. We conclude that caregivers have been instructed and guided, acquiring information and conditions to initiate the rehabilitation process at home.
\end{abstract}

Keywords: Occupational Therapy, Stroke, Caregivers.

\footnotetext{
Autor para correspondência: Natalia Cristina Thinen, Faculdade de Filosofia e Ciência, Universidade Estadual Paulista, Av. Hygino Muzzi Filho, 737, CEP 17525-900, Marília, SP, Brasil, e-mail: nataliathinen@ gmail.com Recebido em 17/6/2009; $1^{a}$ Revisão em 5/10/2010; $2^{a}$ Revisão em 23/1/2012; Aceito em 15/5/2012.
} 


\section{Introdução}

Atualmente, no Brasil estão ocorrendo várias mudanças sociais, destacando-se o acelerado processo de envelhecimento populacional, o aumento da expectativa de vida e a elevação do índice de doenças crônicas degenerativas. Lessa (1999) relata que doenças do sistema circulatório são causa isolada de mortalidade, correspondendo a 32,3\% dos óbitos. Desse grupo, as doenças cerebrovasculares (DCV) correspondem a um terço dos óbitos anuais no Brasil de 1980 a 1995.

As DCV incidem com maior frequência na idade avançada, período da vida em que se observam as maiores taxas de óbito e sequelas. Mas nos últimos anos está crescendo a incidência na população jovem, devido a condiçôes hereditárias e ao uso de drogas ilícitas (PIRES; GAGLIARDI; GORZONI, 2004). O fato das DCV atingirem pessoas em idade produtiva tem um forte impacto econômico, representado em anos produtivos de vida perdidos, custos de hospitalização, uso de serviços de saúde e aposentadoria precoce por invalidez (BOCCHI; ANGELO, 2005).

$\mathrm{O}$ acidente vascular cerebral (AVC) se caracteriza pela instalação de um déficit neurológico focal repentino e não convulsivo, determinado por uma lesão cerebral secundária a um mecanismo vascular e não traumático; ocorre quando os vasos sanguíneos cerebrais são bloqueados ou se rompem e são classificados em dois tipos: isquêmico e hemorrágico (JOHNSTONE, 1986).

As principais sequelas apresentadas sáo a hemiplegia contralateral, hemianopsia, perda visual ipsilateral, afasia, disgrafia, acalculia, agnosia, distúrbios sensoriais, perda da propiocepção, hipoestesia, negligência unilateral e apraxia (ARES, 2003).

Para autores como Rocha e Mello (2004), a intervenção do terapeuta ocupacional (TO) em hospital deve promover açóes que melhorem ao máximo a comunicação entre o paciente, a família e a equipe como parceiros da situação. Dessa forma, o terapeuta ocupacional estará instrumentalizando o paciente e a família para o resgate de sua autonomia e independência nas atividades de vida diária (AVDs) e proporcionando-lhe oportunidades de escolha e de tomadas de decisóes.

Para Mello e Macini (2007), atividades de vida diária (AVDs) são as atividades relacionadas com o cuidado do indivíduo para com seu próprio corpo. As AVDs incluem: higiene pessoal e autocuidado (cuidar dos cabelos e unhas, realizar limpeza oral, aplicar maquiagem, remover pelos do corpo), banho (ensaboar-se, secar-se, manter as posiçóes para o banho, realizar as transferência), alimentação (ato de servir e alimentar-se ou beber), comer (capacidade de receber alimento na boca, mastigar e engolir), vestuário (seleção de roupas e acessórios adequados, vestir-se e despir-se adequadamente, colocar e tirar sapatos ou sandálias), controle de esfíncteres (capacidade de controle de esfíncteres ou utilização de equipamentos de auxílio para esse controle), mobilidade funcional (realizar movimentos e mudanças de posição na cama/cadeira de rodas, transferência, deambulação funcional) cuidado com equipamento pessoais (utilização e limpeza de aparelhos auditivos, lentes de contato, órteses, próteses), atividade sexual (envolvimento em atividades de contentamento sexual), uso do vaso sanitário (manejo de roupas, transferência, limpeza do corpo e cuidados íntimos), dormir e descansar.

O processo de reabilitaçáo do paciente que sofre um AVC inicia-se na fase de hospitalização. As intervençóes devem começar logo que o paciente estiver clinicamente estável e essa assistência imediata é necessária para garantir maior recuperação das funçóes motoras e sensório-perceptivas. A falta de orientaçáo quanto ao posicionamento no leito e o atraso no início da estimulação sensorial podem acarretar perdas significativas na evolução e na recuperação do quadro de lesão (CARVALHO, 2004).

O planejamento de alta deverá começar no momento da internaçáa, com objetivos centrados na necessidade de reabilitar, organizar o ambiente de vida da melhor forma possível e assegurar a continuidade dos cuidados após a alta. O terapeuta ocupacional em um ambiente de cuidados intensivos deverá instruir e orientar os cuidadores para que eles colaborem no processo de reabilitação (WOODSON, 2005).

Segundo Motta e Ferrari (2004), a participação da família é fundamental no processo de recuperação do paciente durante o período de alta hospitalar. $\mathrm{O}$ paciente precisa sentir-se seguro e apoiado em suas necessidades para que se efetivem as orientaçôes da equipe multidisciplinar. $\mathrm{O}$ terapeuta ocupacional deve orientar o acompanhante, seja ele um familiar cuidador ou um cuidador formal, pois esse acompanhamento irá refletir na recuperação. O processo de reabilitação na assistência domiciliar inicia-se com a compreensão e aceitação do cuidado, seguida pela empatia do cuidador, gerando coparticipação ativa nas etapas da estabilizaçáo do equilíbrio da saúde e possibilitando, finalmente, a reabilitaçáo do indivíduo como um todo, corpo e mente. 
A criação de manuais ocorre para facilitar o trabalho da equipe multidisciplinar na orientação de pacientes e familiares no processo de tratamento, recuperação e autocuidado. Dispor de material educativo e instrutivo facilita e uniformiza as orientaçôes com objetivos primários de saúde. Por outro lado, é também uma forma de ajudar os indivíduos no sentido de entenderem melhor o processo de saúde-doença e trilharem os caminhos da recuperação (ECHER, 2005).

\section{Objetivo}

Orientar e preparar os cuidadores de pacientes com AVC para retorno ao domicílio durante o momento da alta hospitalar por meio de orientação verbal, finalizando com a entrega de um manual de orientaçáo de posicionamento e execução de atividades de vida diária.

\section{Método}

Este estudo foi realizado no Hospital das Clínicas da Faculdade de Medicina de Marília (FAMEMA), com aprovação do Comitê de Ética em Pesquisa Envolvendo Seres Humanos, protocolo no 352/07, no período de setembro a novembro de 2007.

Participaram deste estudo 10 pacientes entre 41 e 77 anos que estavam internados no Hospital de Clínicas da Faculdade de Medicina de Marília e 10 cuidadores.

\section{Materiais}

Foram utilizados os seguintes impressos para a coleta de dados: Manual de orientação de posicionamento e execução de AVDs para paciente com AVC (Figuras 1 e 2) e Questionário de avaliação do manual (Quadro 1).

\section{Manual de orientação de posicionamento e execução de AVDs para paciente com AVC}

O manual foi elaborado com orientaçóes seguidas de ilustraçôes para facilitar a compreensão e o entendimento das informaçóes. É composto por vários assuntos e temas importantes no processo de reabilitação. Segue a relação dos tópicos que compóem o manual:

- Apresentação;

- O que é derrame/AVC - acidente vascular cerebral?;
- Tratamento inicial após o derrame;

- Como evitar complicaçóes;

- Reabilitação;

- Cuidados e providências;

- Úlceras de pressão;

- Posicionamento no leito;

- Posicionamento na cadeira e/ou no banco;

- Posicionamento na cadeira de rodas;

- Cuidados e estimulaçáo motora com o braço hemiplégico;

- Orientaçóes para AVD - atividade de vida diária;

- Transferência da cadeira para a cama;

- Lavar o rosto e limpeza da boca;

- Adaptaçáo e/ou mudança no ambiente domiciliar;

- Comunicação com o paciente;

- Referencial bibliográfico.

\section{Procedimentos}

Este estudo é resultado do trabalho realizado pela aluna do $4^{\circ}$ ano de Terapia Ocupacional da Universidade Estadual Paulista (UNESP) de Marília para elaboração do trabalho de conclusão de curso, com a supervisáo de um docente dessa faculdade.

A primeira fase do estudo foi dedicada à elaboraçáo do manual por meio de pesquisa bibliográfica, com análise da opinião de autores que estudam o processo de reabilitação do paciente com AVC e a coleta de informaçôes com os profissionais que atuam na área de reabilitação neurológica a respeito das principais dificuldades, necessidades e cuidados de um paciente com AVC durante sua rotina diária.

Após a elaboração, o manual foi entregue ao primeiro avaliador, formado em Terapia Ocupacional e especializado em Neurologia. Após feitas as correçôes sugeridas pelo primeiro avaliador, o manual foi encaminhado a um segundo avaliador, formado em Fisioterapia e especializado em Neurologia. Ambos os profissionais trabalham com a reabilitação de pacientes hemiplégicos.

No primeiro contato com cada cuidador, a estagiária os orientou quanto a posicionamento no leito, transferência de posiçôes, AVDs e organização do ambiente para, bem como realizou demonstraçóes práticas das atividades de reabilitação, com posterior execução pelo cuidador (repetição), sob sua supervisão. Ao final, um manual de orientação foi entregue a cada um, para que contassem com material de consulta e 
apoio para dar início às orientaçóes e aos cuidados no domicílio. Esse atendimento individual com cada cuidador teve duração média de 40 minutos.

No segundo dia de contato da estagiária, cada cuidador respondeu um questionário cujo objetivo era avaliar o manual. O intervalo de tempo disponibilizado para o familiar analisar o manual foi de dois dias devido às intercorrências da internação: altas, óbitos e transferência dos pacientes.

\section{Resultados e discussão}

Participaram do estudo seis pacientes do sexo masculino e quatro do sexo feminino, com idade

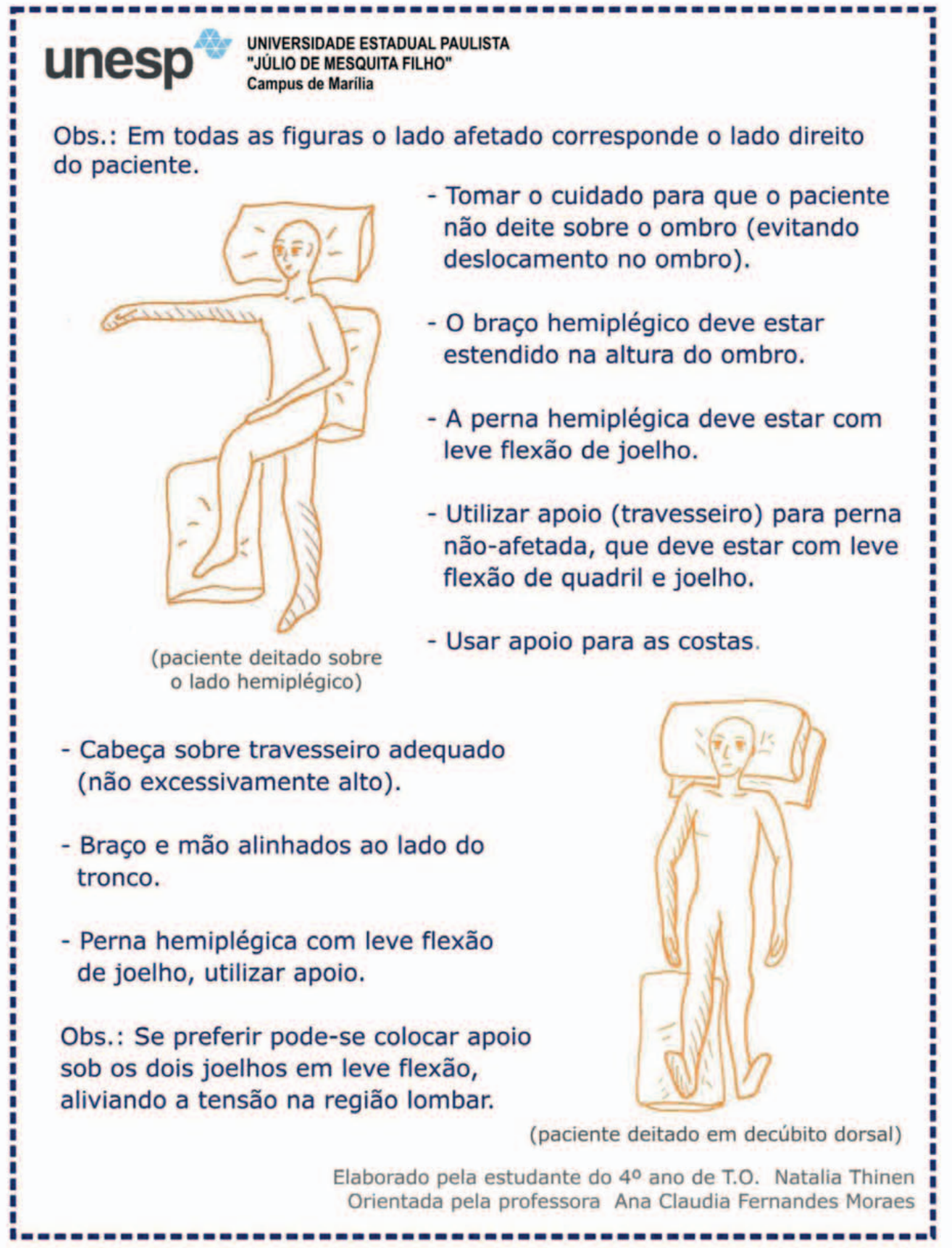

Figura 1. Manual de orientação de posicionamento e execução de atividade de vida diária para pacientes com acidente vascular cerebral. 
entre 41 e 77 anos (média de 63 anos) e desvio padrão de 13,5. Em relação à escolaridade, três tinham o ensino fundamental completo e sete, incompleto. Com relação à ocorrência do AVE (acidente vascular encefálico), para oito deles era a primeira vez, para um deles era a terceira e para o último, a quarta ocorrência.
Entre os cuidadores que participaram do estudo, sete eram do sexo feminino e três do sexo masculino, com idade entre 22 e 53 anos (média de 47 anos) e desvio padrão de 15,8 . Em relação ao grau de parentesco com o paciente, quatro eram filhas, um filho, duas esposas, uma irmá, um sobrinho e um genro. Quanto à escolaridade dos cuidadores: um

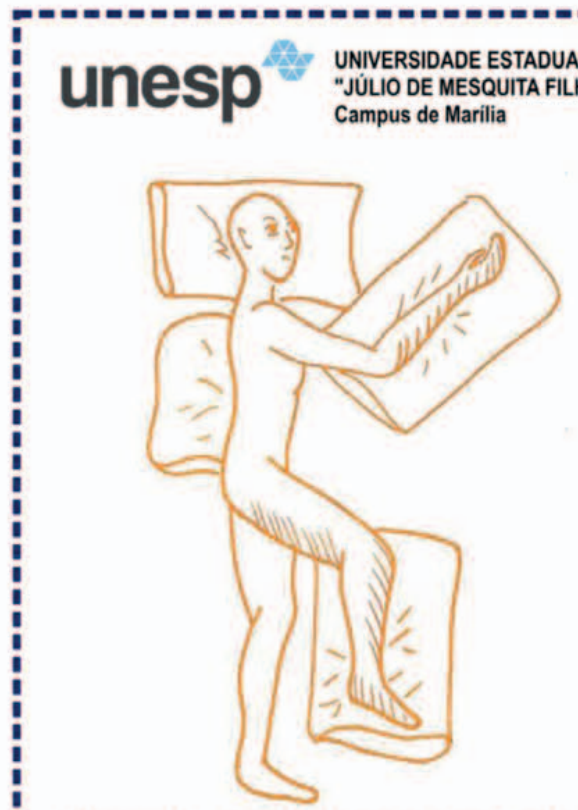

- O braço afetado deve estar em leve flexão de ombro e cotovelo, estando apoiado no travesseiro e com a mão na altura do rosto.

- A perna hemiplégica deve estar com flexão de quadril e joelho utilizando-se apoio (travesseiro).

- Usar apoio para as costas.

(Paciente deitado sobre o lado não afetado)

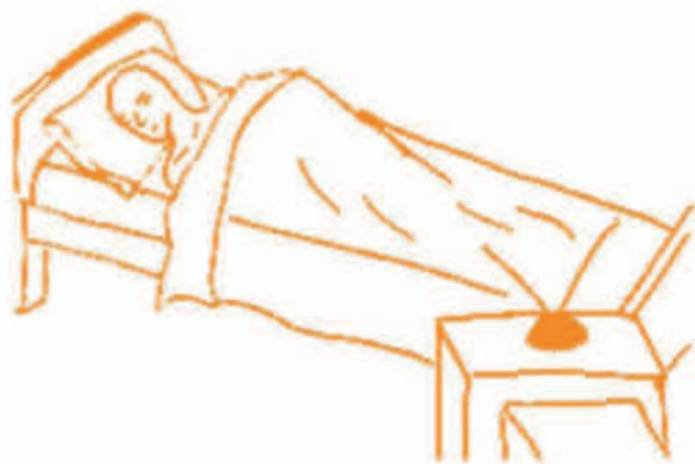

(paciente no leito assistindo televisão)

- Os estímulos visuais, auditivos ou táteis devem estar posicionados do lado hemiplégico Ex: televisão, aparelho de som e etc.

- Quando alguém se aproximar do paciente para conversar deve ficar do lado hemiplégico. Falar normal com o paciente, porém bem devagar.

Figura 2. Manual de orientação de posicionamento e execução de atividade de vida diária para pacientes com acidente vascular cerebral. 
tinha o ensino fundamental completo e dois náo o tinham completado, três tinham o ensino médio completo e três não o tinham completado, o último cuidador tinha ensino superior incompleto.

Qualificar o conteúdo do manual com pacientes e familiares que já vivenciaram de alguma forma a situação nele abordada é uma atitude necessária e um ganho importante para a estagiária e para a equipe envolvida. É um momento em que tomamos conta do que realmente foi entendido (ECHER, 2005).
Os cuidadores receberam um questionário com 13 perguntas para avaliação do manual, que seráo discutidas obedecendo a sua ordem.

Na primeira pergunta foi questionado se o cuidador sabia qual era o posicionamento correto do paciente no leito. Apenas um dos entrevistados respondeu positivamente, os demais desconheciam essa informação, sendo essa orientação de extrema importância, principalmente no período de hospitalização, em que o paciente permanece deitado no leito o dia inteiro.

Quadro 1. Questionário para avaliação do manual de AVC.

1- Antes de conhecer o manual, você sabia qual o posicionamento correto do paciente no leito?
( ) $\operatorname{sim}$
( ) não

2- Algum profissional da saúde (médico, enfermeiro, fisioterapeuta, terapeuta ocupacional) fez essas orientações?
( ) $\operatorname{sim}$
( ) não

3- Você conseguiu entender e/ou compreender o manual e colocar em prática as orientações?
( ) $\operatorname{sim}$
( ) não

4- Considerando as ilustrações, os desenhos, o conteúdo escrito, a clareza das informações e a objetividade, você classifica o manual como:
( ) bom
( ) regular
( ) ruim
5- As ilustrações auxiliaram na compreensão das orientações?
( ) $\operatorname{sim}$
( ) não
6- O texto está suficientemente compreensível?
( ) bom
( ) regular
( ) ruim

7- (A) Você conseguiria realizar as orientações de posicionamento sem ter o manual para consultar?
( ) $\operatorname{sim}$
( ) não

(B) Todas as orientações?
( ) $\operatorname{sim}$
( ) não

(C) Quantas?

\section{(D) Quais?}

8- Tendo o manual em mãos, você se sente:

( ) mais seguro para cuidar do paciente

( ) mais esclarecido sobre o AVC

( ) indiferente

9- As orientações do manual modificaram o seu jeito de cuidar do paciente?
( ) $\operatorname{sim}$
( ) não

10- Que orientações você considerou especialmente importantes?

( ) Posicionamento

( ) Transferência

( ) Atividade de vida diária (comer, tomar banho e higiene pessoal)

( ) Organização do ambiente

11- Dessas orientações, qual você considerou a mais importante?

12- Você recomendaria o manual a familiares de outras pessoas com AVC?
( ) $\operatorname{sim}$
( ) não

13- Que outras orientações você acha que deveriam constar no manual? 
O papel do cuidador é muito importante na fase inicial para prevenir a instalaçáo do espasmo muscular por meio de um bom posicionamento no leito. A posição correta deve ser contrária à atitude espástica, o que deve tornar-se um hábito na vida do paciente hemiplégico (ARAÚJO; CALDAS, 1998).

Quando questionado na segunda pergunta se algum profissional tinha passado orientaçôes de posicionamento, o resultado obtido que apenas dois cuidadores receberam informaçôes a respeito do posicionamento. Essa informação expóe a deficiência no serviço de saúde de uma assistência básica que é considerada fundamental.

Programas de reabilitação têm contribuído significativamente para diminuir os danos causados pela doença porém, para que o êxito seja alcançado, é fundamental que se iniciem o mais cedo possível as medidas de reabilitação, como forma de garantir uma recuperação eficaz, que deve ser iniciada assim que o quadro clínico estabiliza-se (PERLINI; FARO, 2005).

$\mathrm{Na}$ pergunta três, os entrevistados foram interrogados se conseguiram compreender o manual. Todos responderam que sim, após terem escutado da estagiária a explicação de todas as orientações no manual.

As equipes multiprofissionais que atuam em hospitais precisam estar conscientes de que a internação representa uma situação temporária na vida de seus pacientes, enquanto a família é uma instituição permanente que os assiste, sendo essencial, portanto, a orientação tendo em vista a capacitação das famílias para o cuidado do paciente, em especial no caso de doenças que possam necessitar de um período de reabilitaçáo demorado como o AVC (ANDRADE; RODRIGUES, 1999).

Levando em consideração a necessidade de oferecer um melhor suporte ao cuidador no domicílio foi elaborado o manual, para que as orientaçóes possam ser consultadas a qualquer momento. $\mathrm{Na}$ pergunta quatro questiona-se aos entrevistados como eles classificavam o manual dentre as alternativas bom, regular e ruim. Todos classificaram o manual como bom.

Um material bem escrito ou uma informação de fácil entendimento melhora o conhecimento e a satisfação dos pacientes, desenvolve suas atitudes e habilidades, facilita-lhes a autonomia, promove sua adesão, torna-os capazes de entender como as próprias ações influenciam seu padrão de saúde, favorece sua tomada de decisão, enfim, é uma forma de promover saúde (MOREIRA; NÓBREGA; SILVA, 2003).
$\mathrm{Na}$ quinta pergunta questionamos a necessidade das ilustraçôes para a compreensão do manual e, segundo as respostas dos entrevistados, podemos considerar por unanimidade que as figuras ilustrativas sáo de extrema importância para o entendimento da orientação. Considerando que a orientação escrita acompanhada pela figura ilustra, exemplifica e permite uma melhor assimilação da informaçáo.

No momento da elaboração do manual, uma das principais preocupaçóes foi utilizar uma linguagem clara e objetiva, vocabulário simples, sem utilização de termos técnicos, para facilitar a compreensão das informaçôes e construir uma leitura atrativa, organizada e envolvente que despertasse o interesse do cuidador e o estimulasse a consultar o manual sempre que necessário.

$\mathrm{Na}$ sexta pergunta verificou-se essa preocupação e, dentre as possíveis alternativas bom, regular e ruim, todos os entrevistados consideraram que o texto está compreensível, ou seja, todos assinalaram a alternativa bom.

$\mathrm{Na}$ pergunta sete, os entrevistados foram questionados se conseguiriam realizar as orientaçóes sem ter o manual em mãos e todos responderam que não. Nota-se que as orientaçôes não podem se restringir apenas à comunicação verbal, existe a necessidade da comunicação visual e impressa que possa ser consultada em momentos de dúvidas. A intervenção educação em saúde, para ser completa, deve contemplar as duas formas de comunicação.

$\mathrm{Na}$ oitava pergunta questionamos as mudanças emocionais e de enfrentamento que o cuidador passou a vivenciar após estar com o manual em mãos e obtivemos oito respostas para a alternativa mais seguro, cinco para mais esclarecido e zero para indiferente, sendo que três cuidadores assinalaram mais de uma alternativa.

A educação do paciente e da família é uma parte integrante do processo de reabilitação desde o início, o que torna crucial que as famílias e os pacientes compreendam as alteraçóes que ocorreram durante o processo. Que eles possam acessar as mesmas informaçôes várias vezes, para compreender todas as alteraçóes pelas quais estão passando no momento. Quanto mais cedo as famílias são envolvidas nos cuidados do ente querido, mais fácil compreendem e tornam-se parte do processo (PULASKI, 2002).

A pergunta nove questiona os entrevistados se as orientaçôes do manual modificaram sua maneira de cuidar do paciente e todos os cuidadores responderam positivamente. A utilização do manual atuou sobre o processo de modificação de comportamento e compreensão da doença, embora cada cuidador tenha 
seu jeito próprio de cuidar, eles perceberam que era necessário agregar e seguir as novas orientações, modificando esse jeito anterior de se relacionar com o paciente com AVE.

De acordo com Chagas e Monteiro (2004), as orientaçóes socioculturais das pessoas em relação à saúde e ao modo de cuidar da família são ditadas por sua cultura e serão, ou não, as condiçôes em que a aceitaçáo da prestação do cuidado ao familiar doente acontece.

A pergunta 10 busca verificar com os cuidadores qual orientação consideraram a mais importante. Nesta pergunta obtivemos os seguintes resultados: posicionamento (7), atividade de vida diária (5), organização do ambiente (4), transferência (3) sendo que alguns entrevistados assinalaram mais de uma alternativa e, dessa maneira, percebemos uma preocupaçáo um pouco maior com o posicionamento dos pacientes.

$\mathrm{Na}$ questão 11 foi perguntado aos participantes qual a orientaçáo ele considerou a mais importante dentre todas e, como se tratava de uma pergunta aberta, obtivemos as seguintes respostas: organizaçáo do ambiente (3), transferência (2), AVDs (2), posicionamento (2) e todas as orientaçóes (1). Como se trata de uma pergunta subjetiva, as respostas refletem o que cada participante considerou importante dentre todas as informaçóes recebidas. Devemos considerar que todos os participantes receberam a mesma informação.

Na pergunta 12 questionamos se os cuidadores recomendariam o manual a familiares de outras pessoas com AVC e os 10 participantes responderam positivamente. A inexperiência no cuidar gera sentimentos como insegurança, medo e culpa, situaçôes que podem ser amenizadas pelas orientaçóes corretas. Torna-se compreensível que os familiares recomendem o manual para outros familiares que estão passando por essa situação e vivenciando os mesmos sentimentos.

Na questâo aberta de número treze foi perguntado aos cuidadores que tipo de orientaçóes, além das anteriores, deveriam constar no manual. Quatro pessoas não responderam essa pergunta e dos demais obtivemos as seguintes respostas: "o manual está completo" (3), "acredito que o manual está bom" (2); e "o manual está completo, mas poderia falar um pouco sobre alimentação" (1).

Apenas uma pessoa sugeriu mudanças no manual, que deveria contemplar mais informaçóes a respeito da alimentação. Percebemos a necessidade de realizar um trabalho com equipe multidisciplinar para elaboração de um manual mais completo e que atenda todas as necessidades do paciente.

\section{Conclusão}

As vantagens e os benefícios para o paciente são maiores, quando os familiares inicialmente recebem após o AVC orientação e informaçóes sobre a reabilitação. Mas para que isso aconteça é necessário que os órgãos gestores da saúde pública e privada invistam em programas e/ou tratamentos precoces de reabilitaçáo, que devem iniciar no período de hospitalização. Os benefícios desse investimento poderão ser apreciados a longo prazo.

Através do manual é possível que o cuidador e/ou paciente consulte possíveis dúvidas sobre as orientaçôes dadas pelo profissional da saúde no hospital.

A proposta de orientação e preparo do cuidador para receber o paciente com AVC no domicílio é fundamental para eliminar interrupçóes no processo de reabilitação do paciente. Considerando que o ambiente domiciliar é o local onde ocorrem as relaçóes interpessoais do paciente, onde ele passa a maior parte do tempo e realiza as principais atividades da vida cotidiana.

\section{Referências}

ANDRADE, O. G.; RODRIGUES, R. A. P. O cuidado familiar ao idoso com seqüela de acidente vascular cerebral. Revista Gaúcha de Enfermagem, Porto Alegre, v. 20, n. 2, p. 90-109, 1999.

ARAÚJO, T. D.; CALDAS, P. C. Posicionamento no leito. In: CALDAS, P. C. A Saúde do Idoso: A arte de cuidar. Rio de Janeiro: UFRJ, 1998. p. 164-170.

ARES, M. J. J. Acidente Vascular Encefálico. In: TEIXEIRA, E. et al. Terapia Ocupacional na Reabilitação Física. São Paulo: Roca, 2003. p. 3-15.

BOCCHI, S. C. M.; ANGELO, M. Interação cuidador familiar-pessoa com AVC: autonomia compartilhada. Ciência e Saúde Coletiva, Rio de Janeiro, v. 10, n. 3, p. 729-738, jul./set. 2005. http://dx.doi.org/10.1590/ S1413-81232005000300029

CARVALHO, L. M. G. Terapia Ocupacional na reabilitação de pacientes neurológicos adultos. In: CARLO, M. M. R. P.; LUZO, M. C. M. Terapia Ocupacional Reabilitação Física e Contextos Hospitalares. São Paulo: Roca, 2004. p. 200-232.

CHAGAS, N. R.; MONTEIRO, A. R. M. Educação em saúde e família: o cuidado ao paciente, vítima de acidente vascular cerebral. Acta Scientiarm Health Sciences, Maringá, v. 26, n. 1, p. 193-204, 2004. http://dx.doi.org/10.4025/ actascihealthsci.v26i1.1663

ECHER, C. I. Elaboração de manuais de orientação para cuidado em saúde. Revista Latino-Americana de Enfermagem, Ribeirāo Preto, v.13, n. 5, p. 754-757, set./out. 2005. http://dx.doi.org/10.1590/S0104-11692005000500022 
JOHNSTONE, M. Tratamento domiciliar do paciente hemiplégico. São Paulo: Atheneu, 1986.

LESSA, I. Epidemiologia das doenças cerebrovasculares no Brasil. Revista da Sociedade de Cardiologia do Estado de São Paulo, São Paulo, v. 9, n. 4, p. 509-518, 1999.

MELLO, M. A. F.; MANCINI, M. C. Métodos e técnicas de avaliação nas áreas de desempenho Ocupacional. In: CAVAlCANTI, A.; GALVÂO, C. R. C. Terapia Ocupacional: fundamentação e prática. Rio de Janeiro: Guanabara, 2007. p. 49-54.

MOTTA, M. P.; FERRARI, M. A. C. Intervenção terapêutica-ocupacional junto a indivíduos com comprometimento no processo de envelhecimento. In: CARLO M. M. R. P.; LUZO M. C. M. Terapia Ocupacional: reabilitação física e contextos hospitalares. São Paulo: Roca, 2004. p. 300-301.

MOREIRA, M. F.; NÓBREGA, M. M. L.; SILVA, M. I. T. Comunicação escrita: contribuição para a elaboração de material educativo em saúde. Revista Brasileira de Enfermagem, Rio de Janeiro, v. 56, n. 2, p. 184-188, mar./abr. 2003. http://dx.doi.org/10.1590/ S0034-71672003000200015
PERLINI, N. M. O. G.; FARO, A. C. M. Cuidar de pessoa incapacitada por acidente vascular cerebral no domicilio: o fazer do cuidador familiar. Revista da Escola de Enfermagem da USP, São Paulo, v. 39, n. 2, p. 154-163, jun. 2005. http://dx.doi.org/10.1590/S0080-62342005000200005 PIRES, S. L.; GAGLIARDI, R. J.; GORZONI, M. L. Estudo das freqüências dos principais fatores de risco para acidente vascular isquêmico em idosos. Arquivo de Neuropsiquiatria, São Paulo, v. 62, n. 3b, p. 844-85, set. 2004. http://dx.doi.org/10.1590/ S0004-282X2004000500020

PULASKI, K. H. Disfunção neurológica no adulto. In: NEISTADT, M. E.; CREPAU, E. B. Willard \& Spackman: Terapia Ocupacional. 9. ed. Rio de Janeiro: Guanabra Koogan, 2002. p. 617-623.

ROCHA, E. F.; MELLO, M. A. F. Os sentidos do corpo e da intervenção hospitalar. In: CARLO M. M. R. P.; LUZO M. C. M. Terapia Ocupacional: reabilitação física e contextos hospitalares. São Paulo: Roca, 2004. p. 29-46. WOODSON, A. M. Acidente Vascular Cerebral. In: TROMBLY, K. A.; RADOMSKI, M. V. Terapia Ocupacional para disfunção física. 5. ed. São Paulo: Livraria Santos Editora, 2005. p. 817-853.

\section{Contribuição dos Autores}

Natalia Cristina Thinen e Ana Claudia Fernandes Moraes foram responsáveis pela concepção e desenvolvimento e redação final do manuscrito. 